\title{
Leptomeningeal contrast enhancement and blood-CSF barrier dysfunction in aseptic meningitis \\ OPEN
}

Angelika Alonso, MD* Philipp Eisele, MD* Anne D. Ebert, PhD Martin Griebe, MD Britta Engelhardt, PhD

Kristina Szabo, MD

Michael G. Hennerici, MD

Achim Gass, MD

Correspondence to

Dr. Alonso:

alonso@neuro.ma.uni-heidelberg.de

\section{ABSTRACT}

Objective: To investigate the blood-CSF barrier (BCSFB) dysfunction in aseptic meningitis.

Methods: In our case series of 14 patients with acute aseptic meningitis, we compared MRI characteristics with CSF findings.

Results: Contrast enhancement in the sulcal space in a leptomeningeal pattern was visualized in 7 patients with BCSFB dysfunction categorized as moderate to severe as evidenced by the $\mathrm{CSF} /$ serum albumin ratio $\left(\mathrm{Q}_{\mathrm{alb}}\right)$ but was not present in those with mild or no barrier disturbance ( $p=0.001$ ). The $\mathrm{Q}_{\mathrm{alb}}$ as a marker for the leakiness of the BCSFB and, more indirectly, of the blood-brain barrier (BBB) was positively correlated with the incidence of leptomeningeal contrast enhancement seen on postcontrast fluid-attenuated inversion recovery (FLAIR) MRI ( $p=0.003)$. Patients with a more pronounced brain barrier dysfunction recovered more slowly and stayed longer in the hospital.

Conclusions: The severity of meningeal BBB disturbance can be estimated on postcontrast FLAIR MRI, which may be of diagnostic value in patients with aseptic meningitis. Neurol Neuroimmunol Neuroinflamm 2015;2:e164; doi: 10.1212/NXI.0000000000000164

\section{GLOSSARY}

BBB = blood-brain barrier; BCSFB = blood-CSF barrier; CMV = cytomegalovirus; FLAIR = fluid-attenuated inversion recovery; $\mathbf{H S V}=$ herpes simplex virus; $\mathbf{Q}_{\mathbf{a l b}}=\mathrm{CSF} /$ serum albumin ratio; $\mathbf{Q}_{\mathbf{l g G}}=\mathrm{CSF} /$ serum IgG ratio; $\mathbf{V Z V}$ = varicella-zoster virus.

The term "aseptic meningitis" encompasses nonbacterial inflammation syndromes of the meninges predominantly caused by viral infections. ${ }^{1}$ All viral pathogens share a common step in their pathophysiology when traversing brain barriers followed by penetration into the CNS. In their function to maintain CNS homeostasis, blood-brain barrier (BBB) endothelial cells also restrict the entry of both pathogens and immune cells. Meningeal CNS microvessels on the surface of the brain also establish a barrier with somewhat different morphology in order to separate the CSF-drained leptomeningeal space from the blood. ${ }^{2}$ In viral meningitis, disruption of the brain barriers occurs mostly via indirect effects of the virus on the immune system, including induction of chemokines and cytokines and leukocyte homing, among others. ${ }^{3}$ Disintegration of the brain barriers, in turn, can lead to efficient viral clearance by enhanced infiltration of immune cells into the CNS but may also cause a fatal clinical course with propagation to encephalitic involvement and entry of deleterious serum molecules into the brain parenchyma.

The diagnosis of meningitis is based on the combination of typical clinical symptoms and positive CSF findings. Whereas an increase in CSF leukocyte count reflects the inflammatory reaction with transmigration of immune cells into the CSF, the CSF/serum albumin ratio $\left(\mathrm{Q}_{\text {alb }}\right)$ indicates a leakage of blood-borne proteins due to blood-CSF barrier (BCSFB) dysfunction and,

\footnotetext{
*These authors contributed equally to this manuscript.

From the Department of Neurology (A.A., P.E., A.D.E., M.G., K.S., M.G.H., A.G.), Universitätsmedizin Mannheim, University of Heidelberg, Mannheim, Germany; and Theodor Kocher Institute (B.E.), University of Bern, Bern, Switzerland.

Funding information and disclosures are provided at the end of the article. Go to Neurology.org/nn for full disclosure forms. The Article Processing Charge was paid by the authors.

This is an open access article distributed under the terms of the Creative Commons Attribution-NonCommercial-NoDerivatives License 4.0 (CC BY-NC-ND), which permits downloading and sharing the work provided it is properly cited. The work cannot be changed in any way or used commercially.
} 
more indirectly, BBB dysfunction. MRI is commonly used to evaluate complications such as encephalitic involvement, hydrocephalus, or cerebral vasculitis with subsequent ischemia. However, recent work has highlighted the role of postcontrast fluid-attenuated inversion recovery (FLAIR) imaging in the detection of leptomeningeal pathologies, including meningitis or meningeal carcinomatosis. ${ }^{4}$ Mainly due to the suppression of CSF signal, postcontrast FLAIR images show a higher sensitivity in delineation of meningeal pathologies. ${ }^{5}$

In our study, we sought to compare CSF findings with postcontrast FLAIR findings in patients with aseptic meningitis.

METHODS In our case series, we analyzed 14 patients from our MRI and clinical database admitted between 2011 and 2014 with CSF-confirmed diagnosis of aseptic meningitis.

Clinical data including age, sex, presenting symptoms and clinical course, duration of hospitalization, medication, and neurologic status at discharge were collected in all patients. Routine CSF analyses included leukocyte count, CSF protein concentration, $\mathrm{Q}_{\mathrm{alb}}$, CSF/serum IgG ratio $\left(\mathrm{Q}_{\mathrm{IgG}}\right)$, CSF culture, CSF serology (herpes simplex virus [HSV] $\mathrm{IgG} / \mathrm{IgM}$, varicella-zoster virus

\section{Figure 1 Reibergram (CSF/serum quotient diagram) of all included patients}

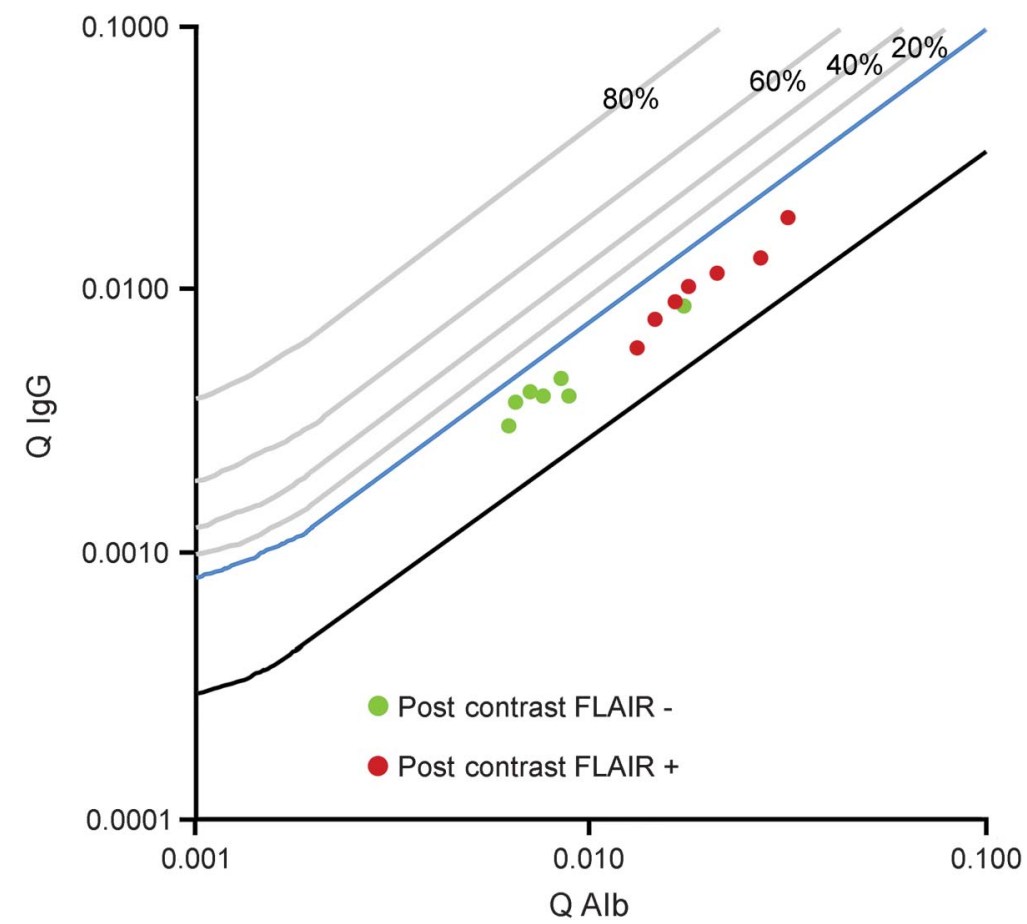

Increasing albumin quotients reflect increasing blood-brain barrier dysfunction (x-axis). The cutoff value for brain barrier dysfunction depends on the patient's age and is therefore not marked. On the $y$-axis, the blue line separates blood-borne lgG (below the line) and intrathecal IgG synthesis (above the line). In our patient cohort, the CSF/serum albumin ratio $\left(Q_{\text {alb }}\right)$ was significantly higher in patients with leptomeningeal enhancement on postcontrast fluidattenuated inversion recovery (FLAIR) imaging (red) than in those without leptomeningeal enhancement (green). $\mathrm{Q}_{\mathrm{ggG}}=\mathrm{CSF} /$ serum IgG ratio.
[VZV] IgG/IgM, measles IgG/IgM, mumps IgG/IgM, Borrelia burgdorferi $\mathrm{IgG/IgM}$, syphilis, HIV), and PCR analysis for neurotropic viruses (HSV 1/2, VZV, CMV, Epstein-Barr virus, enterovirus, human herpesvirus 6). Brain barrier dysfunction and intrathecal synthesis of IgG were determined based on the method of Reiber. ${ }^{6}$ The resulting data are presented in Reibergrams (figure 1), discriminating the $\mathrm{Q}_{\mathrm{IgG}}$ from the $\mathrm{IgG} /$ serum albumin ratio with hyperbolic reference range. The upper limit of the reference range for an intact brain barrier function is agedependent and was calculated for each patient according to the formula $\mathrm{Q}_{\mathrm{alb}}<\left(4+\right.$ age/15) $\times 10^{3}$.7 Brain barrier dysfunction was classified as mild $\left(\mathrm{Q}_{\mathrm{alb}}<10 \times 10^{3}\right)$, moderate $\left(\mathrm{Q}_{\mathrm{alb}} 10-20 \times\right.$ $\left.10^{3}\right)$, or severe $\left(\mathrm{Q}_{\mathrm{alb}}>20 \times 10^{3}\right){ }^{8}$

Clinical data and CSF studies are given in the table.

MRI studies were performed on a 3T MRI system (MAGNETOM Skyra; Siemens Healthcare, Erlangen, Germany) using a standardized protocol including T2-weighted FLAIR echo planar diffusion-weighted imaging including apparent diffusion coefficient calculations and subsequent contrast-enhanced T1-weighted and FLAIR sequences. The MRI data were analyzed with a structured reporting scheme independently by 2 reviewers unaware of clinical detail and experienced with diagnostic and research studies using postcontrast FLAIR MRI.

Statistical analysis was performed using SPSS version 22.0.0.0 (IBM, Armonk, NY). Group comparisons between patients with and without leptomeningeal postcontrast FLAIR hyperintensity regarding the severity of brain barrier dysfunction and CSF protein concentration, $\mathrm{Q}_{\mathrm{alb}}$, and $\mathrm{Q}_{\mathrm{IgG}}$ were calculated by MannWhitney $U$ test and 2-tailed Student $t$ test, as appropriate. A $p$ value $<0.05$ was considered to be statistically significant.

Standard protocol approvals, registrations, and patient consents. This study was approved by the local institutional review board (Medizinische Ethikkommission II der Medizinischen Fakultät Mannheim, University of Heidelberg) and performed in accordance with the ethical standards of the 1964 Declaration of Helsinki and its later amendments. Patient consent was not required by our institutional review board due to the retrospective nature of the study and the lack of patient interaction.

RESULTS During the analyzed period, 15 patients with a diagnosis of aseptic meningitis were examined with a standardized 3T MRI protocol including postcontrast FLAIR sequences and were potentially eligible for the study. One patient had to be excluded due to incomplete CSF workup ( $\mathrm{Q}_{\mathrm{alb}}$ missing).

Fourteen patients ( 8 men, age range $18-58$ years, all immunocompetent) were included in our study. All patients presented with moderate to severe new-onset headache; $8 / 14$ had fever at presentation. In the clinical course, 2 patients developed cranial nerve palsy (abducens nerve in 1 , facial and vestibulocochlear nerve in 1). One patient had new-onset epileptic seizures (table).

On the initial MRI, no parenchymal signal alterations were detected in precontrast sequences including native FLAIR imaging in any of the patients. On postcontrast FLAIR images, 7/14 patients showed leptomeningeal and/or sulcal contrast enhancement. In $4 / 7$, a distinct leptomeningeal enhancement was present along each cerebral lobe of both hemispheres 


\begin{tabular}{|c|c|c|c|c|c|c|c|}
\hline \multicolumn{8}{|c|}{ Clinical data and CSF analyses of the included patients } \\
\hline Age, $y$, sex & Etiology & $\begin{array}{l}\text { Postcontrast } \\
\text { FLAIR }\end{array}$ & $\begin{array}{l}\text { CSF WBC } \\
\text { count, } n / \mu \mathrm{L}\end{array}$ & CSF protein, mg/L & Qalb & $Q_{\operatorname{lgg}}$ & $\begin{array}{l}\text { Brain barrier } \\
\text { dysfunction }\end{array}$ \\
\hline $27, F$ & Viral, CMV & + & 188 & $1,646.6$ & 32.57 & 17.63 & Severe \\
\hline $18, \mathrm{M}$ & ND & + & 436 & $1,526.9$ & 26.28 & 13.22 & Severe \\
\hline $58, \mathrm{~F}$ & ND & + & 97 & 665.8 & 20.88 & 11.95 & Severe \\
\hline $43, \mathrm{M}$ & ND & + & 27 & 586.0 & 13 & 6.5 & Moderate \\
\hline $54, \mathrm{M}$ & Viral, VZV & + & 336 & 938.4 & 16.66 & 10.49 & Moderate \\
\hline 31, M & Viral, HSV2 & + & 491 & 879.6 & 15.2 & 7.32 & Moderate \\
\hline $19, F$ & ND & + & 120 & $1,031.6$ & 15.1 & 8.6 & Moderate \\
\hline $52, \mathrm{M}$ & ND & - & 98 & $1,059.7$ & 16.4 & 8.19 & Moderate \\
\hline $20, \mathrm{~F}$ & ND & - & 170 & 425.4 & 6.9 & 3.71 & Mild \\
\hline $37, \mathrm{~F}$ & Viral, enterovirus & - & 66 & 541.1 & 9.1 & 4.07 & Mild \\
\hline 39, M & ND & - & 48 & 468.6 & 7.49 & 3.9 & Mild \\
\hline $18, M$ & Viral, enterovirus & - & 426 & 396.0 & 6.58 & 3.42 & Mild \\
\hline $26, F$ & Viral, enterovirus & - & 366 & 493.6 & 8.78 & 4.41 & Mild \\
\hline $42, \mathrm{M}$ & Viral, enterovirus & - & 21 & 409.2 & 6.36 & 3.06 & None \\
\hline
\end{tabular}

Abbreviations: $\mathrm{CMV}=$ cytomegalovirus; FLAIR = fluid-attenuated inversion recovery; $\mathrm{HSV}=$ herpes simplex virus; ND = not detectable; $\mathrm{Q}_{\text {alb }}=\mathrm{CSF} / \mathrm{serum}$ albumin ratio; $\mathrm{Q}_{\mathrm{IgG}}=\mathrm{CSF} /$ serum IgG ratio; $\mathrm{VZV}=$ varicella-zoster virus; $\mathrm{WBC}=$ white blood cell.

Brain barrier dysfunction was classified as mild $\left(Q_{a l b}<10 \times 10^{3}\right)$, moderate $\left(Q_{a l b} 10-20 \times 10^{3}\right)$ or severe $\left(Q_{a l b}>20 \times 10^{3}\right)$.

and the cerebellum; in 3/7, contrast enhancement was more subtle and confined to the supratentorial leptomeninges. An example of ubiquitous contrast enhancement of the meninges in a patient with meningitis caused by VZV is given in figure 2. On contrastenhanced T1-weighted images, no parenchymal or meningeal signal abnormalities were noted.

CSF analyses were performed a mean of 2.6 days ( \pm 2.1 days, range $0-8$ days) prior to MRI and showed lymphocytic pleocytosis (mean 206 cells $/ \mu \mathrm{L}$, range 21-491) indicating aseptic meningitis in all patients. There was no evidence of noninfectious aseptic meningitis (postvaccinal, drugs, systemic inflammatory disease, neoplastic disorder) in any of the patients. A specific pathogen was detected in 7 patients. Of these, the 3 patients with leptomeningeal enhancement were infected by Herpesviridae (VZV, HSV2, CMV), whereas the 4 patients without leptomeningeal enhancement were positive for enterovirus RNA. In relation to $\mathrm{Q}_{\operatorname{IgG}}$, none of the patients had intrathecal synthesis of IgG antibodies. In 13/14 patients, $Q_{\text {alb }}$ accounted for a dysfunction of the brain barriers that was classified as severe in $3 / 13$, moderate in $5 / 13$, and mild in $5 / 13$. Patients with leptomeningeal enhancement on postcontrast FLAIR imaging showed significantly higher values of brain barrier dysfunction $(p=0.001)$. Leptomeningeal enhancement on postcontrast FLAIR imaging was present in all but 1 patient with moderate or severe brain barrier dysfunction, whereas none of the patients with mild or no disturbance of the brain barriers showed contrast enhancement of the leptomeninges. The presence of postcontrast leptomeningeal enhancement was associated with higher $\mathrm{Q}_{\text {alb }}(p=0.003)$ and $\mathrm{Q}_{\mathrm{IgG}}(p=0.002)$ as well as a higher CSF protein concentration $(p=0.016)$. Leukocyte count did not differ between patients with or without postcontrast leptomeningeal enhancement $(p=0.449)$. No postlumbar puncture complications occurred.

Clinical outcome was favorable, with resolution of symptoms within 2 weeks in all but 1 patient. This patient showed marked leptomeningeal enhancement and moderate brain barrier disturbance on CSF analysis and had several complications, including sixth cranial nerve palsy, undulating leukocyte count $>100 / \mu \mathrm{L}$ over 4 weeks, and increase of intracranial pressure requiring continuous lumbar CSF drainage for 7 days. In patients without leptomeningeal contrast enhancement, symptoms regressed more quickly than in those showing postcontrast FLAIR signal enhancement. As a result, the average length of hospital stay was longer in patients with leptomeningeal contrast enhancement (mean 19 days vs 7 days in those without enhancing leptomeninges).

DISCUSSION Postcontrast FLAIR MRI sequences have been shown to be valuable in the detection and evaluation of different leptomeningeal diseases, including subarachnoid hemorrhage, meningeosis, and infectious meningitis. ${ }^{9}$ The nulling of the CSF signal due to the inversion time facilitates an optimized delineation of hyperintense pathology adjacent 


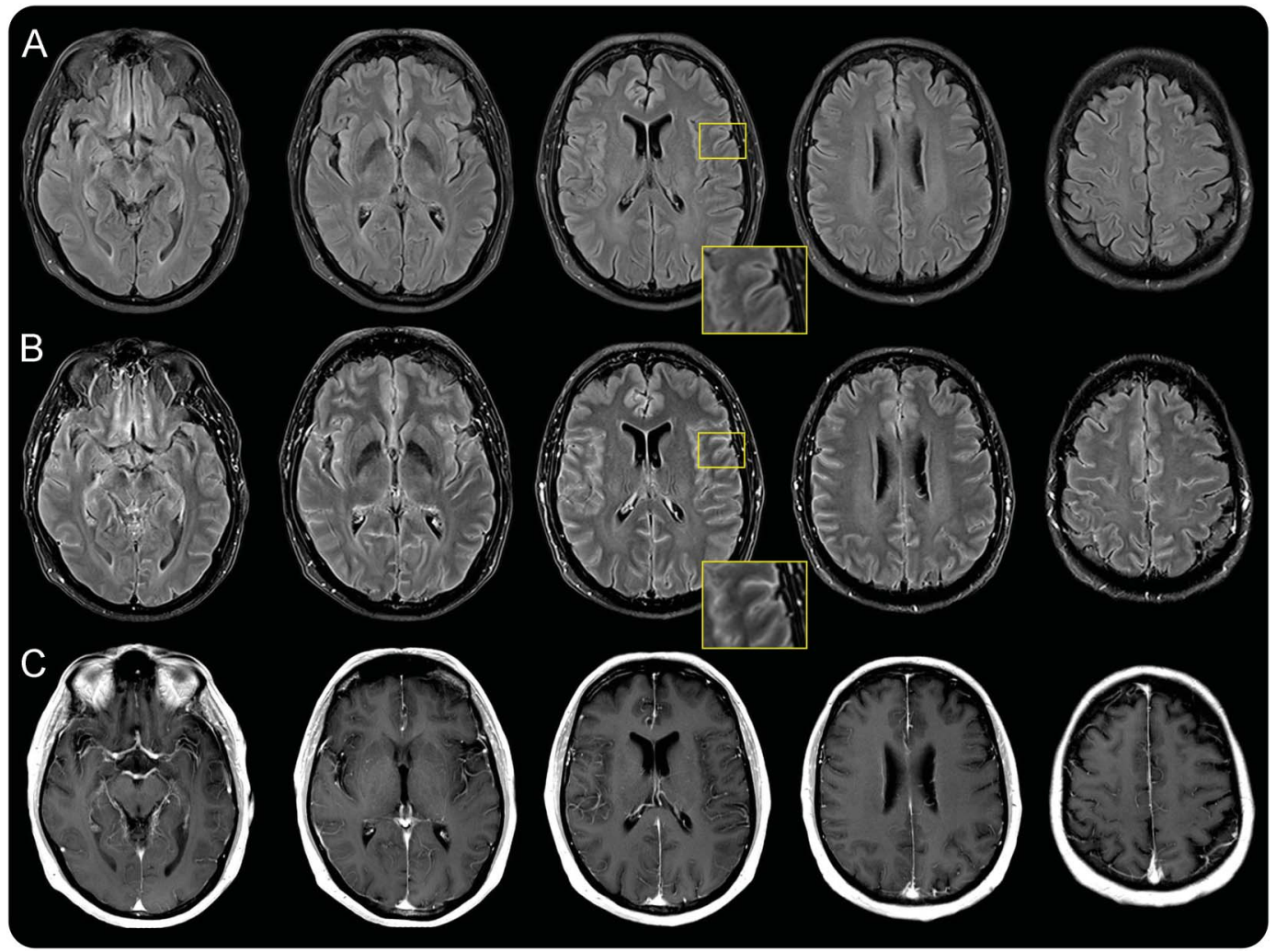

MRI of a 54-year-old patient with viral meningitis caused by varicella-zoster virus. (A) Unenhanced precontrast fluid-attenuated inversion recovery (FLAIR) images. On postcontrast FLAIR images (B), sulcal contrast enhancement and a fine hyperintense lining can be seen, probably involving the leptomeninges in the absence of obvious white or gray matter lesions on both FLAIR and postcontrast T1-weighted MRI (C). The magnified inserts highlight sulcal enhancement.

to the CSF in the sulcal and leptomeningeal space while the T1 shortening in FLAIR sequences is responsible for the highly sensitive delineation of pathologic contrast enhancement following application of gadolinium. ${ }^{10}$ In a large cohort of infants with bacterial meningitis, contrast enhancement of the leptomeninges was the most common pathologic finding on MRI. ${ }^{11}$ From a pathophysiologic point of view, leakage from damaged pial vessels leading to focal extravasation of contrast agent into the CSF adjacent to the brain is the likely cause for leptomeningeal enhancement on FLAIR images. ${ }^{12}$ Contrast enhancement of the leptomeninges on postcontrast FLAIR sequences may thus be a surrogate for dysfunction of the BCSFB and, more indirectly, a marker of $\mathrm{BBB}$ dysfunction. In contrast to patients with ischemic stroke ${ }^{13}$ or cerebral amyloid angiopathy, ${ }^{14}$ in whom localized brain barrier breakdown can be observed, in patients with meningitis a more generalized pattern of contrast enhancement was seen, involving both hemispheres and also the infratentorial space in some patients.

We substantiate this hypothesis by correlating the CSF findings with the presence of leptomeningeal enhancement in patients with aseptic meningitis.
Contrast enhancement of the meninges occurred only in patients with moderate to severe dysfunction of the brain barriers and not in those with mild or no brain barrier disturbance. Moreover, we demonstrate a positive correlation between the $\mathrm{Q}_{\text {alb }}$ as a quantitative marker for brain barrier dysfunction and the occurrence of leptomeningeal enhancement. Partly in line with these findings, an association of $\log 10-$ transformed CSF protein and a leptomeningeal enhancement score has been reported in patients with infectious meningitis. ${ }^{15}$ However, $\log 10$-transformed CSF protein is only an approximate value for brain barrier disturbance, as it is not corrected for serum protein content. The positive correlation may thus be primarily based on the inclusion of patients with bacterial meningitis and marked CSF protein elevation.

Severe damage to the brain barriers, particularly as seen in bacterial meningitis, may predispose to complications and poor prognosis. Accordingly, a positive correlation between the extent of leptomeningeal enhancement on postcontrast FLAIR images and the occurrence of complications has been demonstrated in a study of 43 patients with meningitis of various etiologies. ${ }^{15}$ However, complications affected only 3 patients with bacterial meningitis and 1 patient 
with fungal meningitis, while the clinical course of patients with viral meningitis was benign overall.

Our study focused on patients with aseptic meningitis, characterized by mostly mild to moderate brain barrier dysfunction. Of interest, although only 1 patient in our cohort had a complicated clinical course, the presence of leptomeningeal enhancement still accounted for a delayed resolution of clinical symptoms and a longer hospital stay. On the other hand, a mild increase in brain barrier permeability in patients with viral meningitis may be a precondition for lymphocyte infiltration and subsequent effective viral clearance. $^{16}$ Furthermore, the extent of brain barrier dysfunction may vary depending on the specific viral agent. Viral infections are characterized by individual patterns of chemokine secretion that promote vascular permeability. ${ }^{16}$ In our cohort, 3 patients with leptomeningeal enhancement were infected by Herpesviridae (VZV, HSV2, CMV), coated double-stranded DNA viruses, whereas 4 patients without leptomeningeal enhancement were positive for enteroviruses, uncoated double-stranded RNA viruses. Although data on HSV2 are lacking, HSV1 has been shown to affect the BBB mainly via increased MMP2 and MMP9 activity, leading to collagen type IV degradation. ${ }^{17}$ Instead, in vitro studies have shown that infection of choroid plexus cells with echovirus 30, a member of the enterovirus family, leads to enhanced secretion of CXCL1-3, chemoattractants for T lymphocytes. ${ }^{18}$ This is motivation to study the potential association between viral agents and the occurrence of leptomeningeal enhancement in future cohorts with more patients.

Because contrast-enhanced MRI was performed after CSF analysis, it is theoretically possible that leptomeningeal enhancement was caused or enhanced by the lumbar puncture. However, meningeal enhancement seems to occur only in the case of post-lumbar puncture headache or intracranial hypotension, ${ }^{19}$ which did not occur in any of our patients.

In patients with aseptic meningitis, leptomeningeal enhancement on postcontrast FLAIR images is closely related to the extent of leakage of bloodborne proteins into the CSF. Both leptomeningeal enhancement and $\mathrm{Q}_{\mathrm{alb}}$ can thus serve as surrogate markers for brain barrier dysfunction.

\section{AUTHOR CONTRIBUTIONS}

Angelika Alonso: conceptualization of the study, data acquisition, analysis and interpretation of the data, drafting and revising the manuscript. Philipp Eisele: data acquisition, analysis and interpretation of the data, revising the manuscript. Anne D. Ebert: analysis and interpretation of the data, revising the manuscript, statistical analysis. Martin Griebe: acquisition, analysis, and interpretation of the data, revising the manuscript. Britta Engelhardt: analysis and interpretation of the data, revising the manuscript. Kristina Szabo: acquisition, analysis, and interpretation of the data, revising the manuscript. Michael G. Hennerici: analysis and interpretation of the data, revising the manuscript. Achim Gass: conceptualization of the study, data acquisition, analysis and interpretation of the data, drafting and revising the manuscript.

\section{STUDY FUNDING}

No targeted funding reported.

\section{DISCLOSURE}

A. Alonso is on the editorial board of Advances in Neuroscience. P. Eisele received travel expenses from Bayer Health Care. A.D. Ebert reports no disclosures. M. Griebe received speaker honoraria from Biogen Idec. B. Engelhardt is on the scientific advisory board for Swiss Multiple Sclerosis Society, ARSEP, Cluster of Excellence for Systems Neurology "SyNergy," and Zentrum für Molekulare Neurobiologie; is on the editorial board for European Journal of Immunology, Fluids and Barriers of the CNS, and Acta Neuropathologica; and received research support from Swiss National Science Foundation, Swiss Multiple Sclerosis Society, ARSEP, Bangerther Rhyner Foundation, and Schweizerische Herzstiftung. K. Szabo is on the editorial board for Cerebrovascular Diseases and Case Reports in Neurology and received research support from German Research Foundation. M.G. Hennerici is an editor for Cerebrovascular Diseases and Interventional Neurology, is a consulting editor for International Journal of Stroke, receives publishing royalties from Thieme Publishers, and received research support from TIARegistry. A. Gass received travel funding and/or speaker honoraria from Bayer Schering, Biogen Idec, Merck Serono, Novartis, and TEVA Neurosciences and is on the editorial board for Cerebrovascular Diseases and Journal of Neuroimaging. Go to Neurology.org/nn for full disclosure forms.

Received April 7, 2015. Accepted in final form September 8, 2015.

\section{REFERENCES}

1. Lee BE, Davies HD. Aseptic meningitis. Curr Opin Infect Dis 2007;20:272-277.

2. Engelhardt B, Ransohoff RM. Capture, crawl, cross: the T cell code to breach the blood-brain barriers. Trends Immunol 2012;33:579-589.

3. Spindler KR, Hsu TH. Viral disruption of the blood-brain barrier. Trends Microbiol 2012;20:282-290.

4. Kremer S, Abu Eid M, Bierry G, et al. Accuracy of delayed post-contrast FLAIR MR imaging for the diagnosis of leptomeningeal infectious or tumoral diseases. J Neuroradiol 2006;33:285-291.

5. Ercan N, Gultekin S, Celik H, Tali TE, Oner YA, Erbas G. Diagnostic value of contrast-enhanced fluidattenuated inversion recovery MR imaging of intracranial metastases. AJNR Am J Neuroradiol 2004;25:761-765.

6. Reiber H. Flow rate of cerebrospinal fluid (CSF)-a concept common to normal blood-CSF barrier function and to dysfunction in neurological diseases. J Neurol Sci 1994; 122:189-203.

7. Reiber H, Peter JB. Cerebrospinal fluid analysis: diseaserelated data patterns and evaluation programs. J Neurol Sci 2001;184:101-122.

8. Reiber H, Felgenhauer K. Protein transfer at the blood cerebrospinal fluid barrier and the quantitation of the humoral immune response within the central nervous system. Clin Chim Acta 1987;163:319-328.

9. Maeda M, Yagishita A, Yamamoto T, Sakuma H, Takeda K. Abnormal hyperintensity within the subarachnoid space evaluated by fluid-attenuated inversion-recovery MR imaging: a spectrum of central nervous system diseases. Eur Radiol 2003;13(suppl 4):L192-L201.

10. Mathews VP, Caldemeyer KS, Lowe MJ, Greenspan SL, Weber DM, Ulmer JL. Brain: gadolinium-enhanced fast fluid-attenuated inversion-recovery MR imaging. Radiology 1999;211:257-263.

11. Oliveira CR, Morriss MC, Mistrot JG, Cantey JB, Doern CD, Sanchez PJ. Brain magnetic resonance imaging of infants with bacterial meningitis. J Pediatr 2014;165: 134-139. 
12. Jackson EF, Hayman LA. Meningeal enhancement on fast FLAIR images. Radiology 2000;215:922-924.

13. Latour LL, Kang DW, Ezzeddine MA, Chalela JA, Warach S. Early blood-brain barrier disruption in human focal brain ischemia. Ann Neurol 2004;56:468-477.

14. Barakos J, Sperling R, Salloway S, et al. MR imaging features of amyloid-related imaging abnormalities. AJNR Am J Neuroradiol 2013;34:1958-1965.

15. Lee JS, Park JK, Kim SH, et al. Usefulness of contrast enhanced FLAIR imaging for predicting the severity of meningitis. J Neurol 2014;261:817-822.

16. Hosking MP, Lane TE. The role of chemokines during viral infection of the CNS. PLoS Pathog 2010;6:e1000937.
17. Sellner J, Simon F, Meyding-Lamade U, Leib SL. Herpessimplex virus encephalitis is characterized by an early MMP-9 increase and collagen type IV degradation. Brain Res 2006;1125:155-162.

18. Schneider H, Weber CE, Schoeller J, et al. Chemotaxis of T-cells after infection of human choroid plexus papilloma cells with Echovirus 30 in an in vitro model of the blood-cerebrospinal fluid barrier. Virus Res 2012;170: 66-74.

19. Hannerz J, Ericson K, Bro Skejo HP. MR imaging with gadolinium in patients with and without postlumbar puncture headache. Acta Radiol 1999;40: 135-141. 


\section{Neurology \\ Neuroimmunology \& Neuroinflammation}

\section{Leptomeningeal contrast enhancement and blood-CSF barrier dysfunction in aseptic meningitis \\ Angelika Alonso, Philipp Eisele, Anne D. Ebert, et al. \\ Neurol Neuroimmunol Neuroinflamm 2015;2; \\ DOI 10.1212/NXI.0000000000000164}

This information is current as of October 15, 2015

\section{Updated Information \& \\ Services}

References

Subspecialty Collections

Permissions \& Licensing

Reprints including high resolution figures, can be found at:

http://nn.neurology.org/content/2/6/e164.full.html

This article cites 19 articles, 1 of which you can access for free at: http://nn.neurology.org/content/2/6/e164.full.html\#\#ref-list-1

This article, along with others on similar topics, appears in the following collection(s):

Meningitis

http://nn.neurology.org//cgi/collection/meningitis

MRI

http://nn.neurology.org//cgi/collection/mri

Viral infections

http://nn.neurology.org//cgi/collection/viral_infections

Information about reproducing this article in parts (figures,tables) or in its entirety can be found online at:

http://nn.neurology.org/misc/about.xhtml\#permissions

Information about ordering reprints can be found online:

http://nn.neurology.org/misc/addir.xhtml\#reprintsus

Neurol Neuroimmunol Neuroinflamm is an official journal of the American Academy of Neurology.

Published since April 2014, it is an open-access, online-only, continuous publication journal. Copyright $\odot$ 2015 American Academy of Neurology. All rights reserved. Online ISSN: 2332-7812.

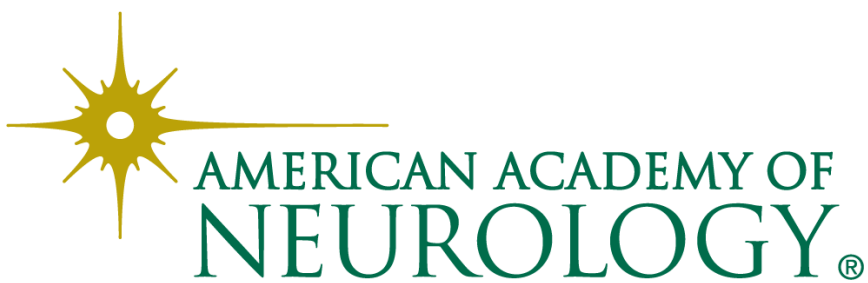

